\title{
Pressupostos, Fundamentos Teóricos e Legado do Curso de Mestrado em Planejamento Governamental Desenvolvido por Alberto Guerreiro Ramos
}

\author{
Assumptions, Theoretical Foundations and Legacy of the Master's Course in Government \\ Planning Developed by Alberto Guerreiro Ramos
}

José Francisco Salm ${ }^{1}$

Universidade Federal de Santa Catarina / Departamento de Ciências da Administração, Florianópolis - SC, Brasil

\begin{abstract}
Resumo
Este artigo identifica e discute os pressupostos e os fundamentos teóricos que orientaram o Curso de Mestrado em Planejamento Governamental, desenvolvido por Alberto Guerreiro Ramos na Universidade Federal de Santa Catarina (UFSC), em 1980 e 1981. Os dados foram obtidos por meio de documentos, material bibliográfico e entrevistas semiestruturadas realizadas com professores e alunos que participaram do curso. Os pressupostos e fundamentos teóricos resultantes dessa pesquisa compõem o conjunto de conhecimentos a partir do qual se desenvolveram os enunciados e as proposições de nossas considerações finais. Tais enunciados e proposições formam um excerto do legado que esse intelectual proporcionou à academia, em especial para a organização e o desenvolvimento de cursos stricto sensu de pós-graduação em Administração.
\end{abstract}

Palavras-chave: Pressupostos. Fundamentos teóricos. Legado. Administração.

\begin{abstract}
This article identifies and discusses the assumptions and theoretical foundations that guided the Master's Course in Government Planning developed by Alberto Guerreiro Ramos at the Federal University of Santa Catarina (UFSC), in 1980 and 1981. Data were obtained by means of documents, bibliographic material, and semi-structured interviews conducted with professors and students who participated in the course. The assumptions and theoretical foundations resulting from this research constitute the set of knowledge through which the statements and propositions of our final remarks were developed. Such statements and propositions form an excerpt of the legacy that this intellectual scholar has provided the academy with, especially for organizing and developing stricto sensu graduate courses in Administration.
\end{abstract}

Keywords: Assumptions. Theoretical foundations. Legacy. Administration.

Artigo submetido em 26 de janeiro de 2015 e aceito para publicação em 15 de junho de 2015.

DOI: http://dx.doi.org/10.1590/1679-395147737

1 Ph.D. em Administração Pública pela Universidade do Sul da Califórnia (USC); Professor titular aposentado da Universidade Federal de Santa Catarina, Departamento de Ciências da Administração. Endereço: Av. Rubens de Arruda Ramos, Centro, 1650, CEP 88.015-700, Florianópolis - SC, Brasil. E-mail: josefrancisco.salm@gmail.com 


\section{Introdução}

A homenagem que a Fundação Getulio Vargas (FGV), por meio de sua Diretoria Internacional, em associação com o Conselho Federal de Administração (CFA) e a Universidade do Sul da Califórnia (USC), presta a Alberto Guerreiro Ramos neste Seminário, pelo seu trabalho como cidadão e acadêmico, oferece a oportunidade de, mais uma vez, trazer-se à baila o legado que esse intelectual proporcionou à academia, em especial aos estudos de Administração. Este artigo se insere nesse propósito, cabendo-lhe discutir o Curso de Mestrado em Planejamento Governamental, realizado por Guerreiro Ramos na Universidade Federal de Santa Catarina (UFSC), em 1980 e 1981. A busca desse propósito torna-se relevante na medida em que a discussão sobre o curso se apropria de seu conteúdo para identificar e compor um corpo de teoria capaz de proporcionar um legado para aqueles que buscam novos conhecimentos e, também, para aqueles que almejam organizar ou desenvolver programas de pós-graduação stricto sensu em Administração. O Curso de Mestrado em Planejamento Governamental, em particular, assim como todos os cursos stricto sensu em Administração, constituiu um empreendimento científico, uma vez que se sustentou sobre bases ontológicas e epistemológicas, bem como sobre teorias, métodos e técnicas que forneceram o amálgama para sua organização e desenvolvimento, além de proporcionar aos seus membros a referência para a autointerpretação.

O objetivo deste artigo segue essa linha de pensamento, uma vez que identifica e discute os pressupostos e os fundamentos teóricos que orientaram o Curso de Mestrado em Planejamento Governamental; ao identificar e discutir os pressupostos e os fundamentos teóricos do curso, espera-se compor um conjunto de conhecimentos como legado desse intelectual à academia, em especial para a organização e o desenvolvimento de cursos stricto sensu de pós-graduação em Administração.

Com tal propósito, o artigo se organiza a partir desta introdução. Na sequência, apresenta-se e descreve-se o curso, identificam-se e discutem-se os pressupostos e as teorias que lhe deram sustentação. As considerações finais oferecem uma síntese do legado que Alberto Guerreiro Ramos proporcionou à organização e ao desenvolvimento de cursos stricto sensu de pós-graduação em Administração.

A orientação metodológica define o estudo do curso como método de caso, com emprego da pesquisa documental e bibliográfica. A coleta de dados foi complementada por entrevistas semiestruturadas com professores e alunos que participaram daquela iniciativa. Para obter os dados sobre as teorias que orientaram o curso, o levantamento dos documentos se restringe à contribuição de Alberto Guerreiro Ramos, uma vez que se almeja identificar seu legado para a organização e o desenvolvimento de programas de pós-graduação stricto sensu em Administração. Doravante o autor será nominado somente Guerreiro Ramos e o Curso de Planejamento Governamental será nominado Curso.

A discussão acerca dos pressupostos e fundamentos teóricos do Curso toma como referência a teoria da delimitação dos sistemas sociais e outras propostas teóricas formuladas por Guerreiro Ramos. Também se deve notar que muitas citações bibliográficas são das décadas de 1970 e 1980 - período em que se insere o contexto do Curso apresentado e descrito.

\section{Apresentação e descrição do Curso}

A proposta do Curso resultou de um convênio entre o Instituto Técnico de Economia e Planejamento (ITEP), da Secretaria de Planejamento do Governo do Estado de Santa Catarina, e a UFSC. Vale destacar que, à época, dirigia a Instituto o Prof. Ubiratan Simões Rezende, a quem se deve a iniciativa do convênio e a viabilização dos recursos necessários para sua implementação. A execução do convênio ficou a cargo do Curso de Pós-Graduação em Administração (CPGA), integrante do Departamento de Ciências da Administração (CAD) e do Centro Socioeconômico (CSE) da UFSC. É necessário lembrar que o CPGA, de criação recente, tinha pouca cultura de estudos e pesquisas de pós-graduação e poucos professores com 
doutorado e experiência em orientação de dissertações. Apenas um professor se filiava à linha de pesquisa sobre a teoria da delimitação dos sistemas sociais. O Curso, realizado em 1980 e 1981, tinha por objetivos:

- Constituir-se como centro de pesquisa em planejamento governamental;

- Promover a pesquisa teórica e aplicada sobre o paradigma da delimitação dos sistemas sociais;

- Realizar estudos sobre o Brasil e países periféricos a partir de sua realidade econômica e cultural;

- Identificar as questões relacionadas com a ordem internacional, estabelecendo as possíveis abordagens teóricas para seu estudo;

- Compor um centro de estudos alternativos ao modelo vigente de mercado e aos programas de pósgraduação stricto sensu convencionais.

Compunham o Curso as seguintes disciplinas:

- Teoria da Delimitação dos Sistemas Sociais;

- Administração Pública e a Organização;

- Administração Delimitativa do Sistema Internacional de Recursos;

- Abordagem Delimitativa do Processo de Formulação, Implementação e Avaliação de Políticas Públicas e Orçamentos Públicos;

- Teoria da Tecnologia Apropriada;

- Paraeconomia dos Sistemas de Produção e as Implicações Delimitativas para uma Economia de Mercado;

- Administração Delimitativa da Alocação dos Recursos Nacionais.

“Teoria da Delimitação dos Sistemas Sociais" era disciplina eliminatória e tinha por objetivo apresentar e discutir as abordagens formais e substantivas da vida humana associada. Também constituíam o propósito da disciplina a análise crítica da sociedade centrada no mercado e a possibilidade de articulação de uma sociedade multicêntrica.

“Administração Pública e a Organização" abordava os estudos da administração pública sob o foco macrossocial, organizacional e suborganizacional. Também realizava uma avaliação crítica da administração pública com base em critérios delimitativos.

"Administração Delimitativa do Sistema Internacional de Recursos" tratava dos limites ecológicos, com ênfase nos recursos renováveis e não renováveis. Fazia, ainda, uma análise dos correlatos termodinâmicos e sua relação com o consumo e a produção.

"Abordagem Delimitativa do Processo de Formulação, Implementação e Avaliação de Políticas Públicas e Orçamentos Públicos", a partir de uma avaliação crítica dos estudos sobre as políticas públicas, propunha uma teoria delimitativa para a implementação e avaliação dessas políticas. No tocante ao estudo dos orçamentos públicos, a disciplina tinha como proposta transformá-los em estratégia para alocação de recursos voltados aos diversos sistemas sociais.

"Teoria da Tecnologia Apropriada" examinava os diversos contextos para o emprego da tecnologia e de seus diferentes conceitos. Discutia, ainda, a transferência da tecnologia e a singularidade de cada contexto. A questão do tamanho dos sistemas sociais estava relacionada à tecnologia apropriada a cada contexto. 
"Paraeconomia dos Sistemas de Produção e as Implicações Delimitativas para uma Economia de Mercado" estudava as transferências de recursos, distinguia os sistemas formais dos informais, discutia o emprego e a ocupação e realizava a análise crítica sobre a natureza formal ou substantiva dos assuntos econômicos.

"Administração Delimitativa da Alocação dos Recursos Nacionais" tratava das teorias da modernização e do desenvolvimento. Associava a modernização e o desenvolvimento à ecologia e às singularidades de cada contexto. Propunha, também, uma teoria delimitativa de macroalocação de recursos.

O corpo docente, originário de diversos campos disciplinares, era composto por professores, doutores recémtitulados e doutorandos em fase de defesa de tese. Apesar de originários de campos disciplinares distintos, eram estudiosos e pesquisadores da delimitação dos sistemas sociais. Os doutores recém-titulados e os doutorandos haviam defendido ou estavam em fase de defesa de suas teses na área da disciplina que ministravam no Curso. Também havia professor convidado, cujas publicações eram adotadas no Curso, uma vez que suas pesquisas contribuíam para o desenvolvimento da teoria da delimitação dos sistemas sociais. Os programas das disciplinas foram desenvolvidos com a colaboração e supervisão de Guerreiro Ramos.

A organização do Curso previa que cada participante deveria completar os créditos e defender sua dissertação - resultado de estudos teóricos empíricos - no prazo máximo de dois anos. O foco dos estudos teóricos seguiria a teoria da delimitação dos sistemas sociais em busca da construção de sistemas sociais alternativos. Já o estudo empírico deveria focar um programa ou projeto voltado à aplicação da teoria da delimitação dos sistemas sociais.

O número de vagas do Curso foi fixado em 20, mas apenas 15 foram selecionados. Destes, 9 obtiveram o total de créditos. O processo de seleção utilizava critérios que pontuavam o desempenho acadêmico do candidato no respectivo curso de graduação, seu curriculum vitae e a capacidade por ele demonstrada para levar a bom termo os estudos e as pesquisas que seriam exigidos ao longo do Curso. Os participantes selecionados eram graduados em Administração e áreas afins, inclusive medicina, agronomia, direito, arquitetura e economia. Vale destacar que eles ingressaram por apresentar grande experiência de trabalho no desenvolvimento e modernização do Estado de Santa Catarina. Dos alunos também se exigia que tivessem fluência em língua inglesa, já que alguns professores lecionavam sua disciplina nesse idioma. Ademais, inúmeros livros e artigos eram escritos em inglês. Nesse caso, eram aplicadas as recomendações da redução sociológica (GUERREIRO RAMOS, 1996).

A metodologia de ensino se valia de aulas expositivas, nas quais o professor discorria sobre o assunto e os alunos eram estimulados a participar ativamente. As disciplinas se desenvolviam em 8 encontros com 4 horas de duração. Para cada encontro, os alunos deveriam ler um conjunto de artigos e trazer um ensaio crítico, de, no máximo, 2 páginas, com cópia para os demais participantes. Pedia-se a cada aluno do Curso que fizesse uma apreciação crítica, em sala, sobre o conteúdo do artigo apresentado. Ao professor cabia a avaliação final do ensaio. Cada disciplina tinha como orientação pedagógica que o aluno fosse centro da aprendizagem e fonte de conhecimento para todo o grupo. A sala de aula era compreendida como um ambiente criativo e intelectualmente estimulante. Ao final da disciplina, cada aluno apresentava ao professor um artigo com, no mínimo, 20 páginas, com tema definido pelo aluno e aprovado pelo professor. A avaliação do artigo levava em conta a capacidade apresentada pelo aluno para operacionalizar conceitos e focar criativamente um problema. Também era aceito, quando bem elaborado, o ensaio teórico que contribuísse para o desenvolvimento da teoria da delimitação dos sistemas sociais. O conjunto de disciplinas tinha como fundamento teórico comum a teoria da delimitação dos sistemas sociais, complementada com a bibliografia própria de cada disciplina.

No próximo tópico são identificados e discutidos os pressupostos que orientaram a estruturação do Curso. A lista dos pressupostos consta na documentação do programa, que ainda está disponível na UFSC. Também foram realizadas entrevistas com participantes do Curso para esclarecer e complementar algumas informações sobre os pressupostos. 


\section{Identificação e discussão dos pressupostos que orientaram o Curso}

Pressupostos, para os efeitos deste artigo, são o conjunto de ideias, diretrizes e fatos tomados como base para a concepção do Curso. Essas ideias, diretrizes e fatos também serviram de sustentáculo e de referência para seu desenvolvimento. Alguns pressupostos estão impregnados com uma visão de mundo e fundamentos ontológicos entendidos como legítimos para a organização, o desenvolvimento e a orientação do Curso. Por via de consequência, os pressupostos definiram os caminhos para a pesquisa realizada, as bases teóricas que serviram de sustentáculo para as disciplinas e a pesquisa, os métodos e as técnicas utilizadas para a abordagem dos fenômenos de natureza empírica. Para os propósitos deste artigo é, pois, mais do que necessário que se identifiquem e discutam os pressupostos que orientaram a concepção e o desenvolvimento do Curso. Alguns pressupostos podem se confundir com as pesquisas e teorias desenvolvidas por Guerreiro Ramos, portanto, pode ocorrer que alguns deles também venham a ser identificados como teorias. Espera-se que a identificação e a subsequente discussão desses pressupostos venham contribuir com o legado que Guerreiro Ramos proporcionou para a organização e o desenvolvimento de cursos stricto sensu de pósgraduação em Administração.

Os pressupostos marcantes que orientaram o Curso, de acordo com os registros dos Cadernos do Curso de Pós-Graduação em Administração (GUERREIRO RAMOS, 1980), foram:

- As mudanças fundamentais que ocorrem em nossa era;

- O declínio da sociedade de mercado e do paradigma que a sustenta;

- As externalidades geradas a partir da orientação do paradigma de mercado que limitam e colocam em risco a vida humana associada;

- Os limites e mesmo a incapacidade das ciências sociais para explicar o complexo fenômeno da mudança;

- A necessidade de buscar um novo paradigma para orientar a reconstrução da vida humana associada;

- A necessidade de conceber e aprender um novo conjunto de conceitos e teorias que possam ser aplicadas e que sejam consentâneas com a transição e as mudanças que estão ocorrendo na vida humana associada;

- A proposta já formulada do paradigma paraeconômico que traça as linhas geais de uma nova teoria de alocação de recursos e da vida humana associada;

- O imperativo de criar condições de praticabilidade para as propostas formuladas a partir do paradigma paraeconômico.

A identificação desses pressupostos possibilita que se realize, agora, uma breve discussão que leve a uma compreensão mais abrangente, dentro do objetivo que se delineou para este artigo. Esta discussão leva em conta, principalmente, os dados obtidos junto aos entrevistados que participaram do Curso e as leituras exigidas na disciplina ministrada por Guerreiro Ramos.

As mudanças fundamentais que ocorrem em nossa era, primeiro pressuposto do Curso, podem ser mais bem compreendidas se discutidas à luz das transformações que ocorreram entre os séculos XVII e XVIII, como relatam Hirschman (2002), Polanyi (1980) e Appleby (1978). Entre esses autores, é Hirschman (2002) quem melhor define a perplexidade diante dos acontecimentos geradores das grandes mudanças que deram origem ao moderno modelo de mercado. Esse autor se mostra surpreso ao constatar como a sociedade aceitou rapidamente uma nova ordem de valores, soterrando outros que haviam perdurado ao longo de séculos.

Esse fato constituiu um pressuposto para o Curso, porque identifica o nascedouro do paradigma vigente, ou seja, a base de valores que legitima as relações formais da vida humana associada subordinada ao sistema de mercado. A partir dessa constatação, o Curso se estruturou sobre uma nova base ontológica e, a partir dela, 
sobre fundamentos epistemológicos próprios. Essa base ontológica e os fundamentos epistemológicos, em oposição ao paradigma de mercado, entendem que o ser humano é multidimensional, a racionalidade também é substantiva e a sociedade é multicêntrica. Essa concepção sobre o ser humano, a racionalidade e a sociedade evidencia-se na documentação do "programa acadêmico e de pesquisa em planejamento governamental" elaborado por Guerreiro Ramos. Pode-se afirmar, então, que a compreensão dos valores inerentes ao paradigma de mercado e de suas origens constitui um pressuposto do Curso, assim como sua base ontológica e epistemológica.

Ainda sobre o aspecto das mudanças fundamentais que ocorrem em nossa era e sua relação com as transformações que se deram entre os séculos XVII e XVIII, cabe citar a questão do controle social. De fato, o controle social que se exercia sobre a sociedade por meio da exigência de cumprimento de algumas virtudes de cunho religioso foi rapidamente substituído pela liberalização do interesse próprio. Entendia-se, de acordo com o relato das pesquisas de Hirschman (2002), que a liberação de uma paixão mais branda, o interesse próprio, serviria para o controle das demais paixões. Tanto Hirschman (2002) como Polanyi (1980) e Appleby (1978) relatam as consequências imediatas dessa transformação dos valores. Entre essas consequências, estava uma nova orientação para o mundo dos negócios, acompanhada por uma rápida adequação da linguagem e dos comportamentos à nova realidade em construção.

Tal fato constitui um pressuposto para o Curso porque, entre as consequências imediatas da mudança, havia uma nova forma de pensar e de conceber a realidade. Os comportamentos também foram direcionados para a legitimação de novos valores, como evidencia Hirschman (2002) em seu relato de pesquisa. Com base nessas evidências e nesses fatos, o programa do curso estruturou-se sobre uma visão crítica dessa forma de pensar, de conceber a realidade, e dos comportamentos induzidos pelo paradigma de mercado. Analisado o programa do Curso, observa-se que essa visão crítica também perpassa as disciplinas. Esse fato, é curioso observar, leva muitos autores a identificar a obra de Guerreiro Ramos como integrante de um grupo de autores e pesquisadores da teoria crítica. De fato, parte da obra se abriga sob o manto da teoria crítica, mas as teorias do autor não se esgotam na crítica, já que o objetivo principal de seu trabalho encontra-se na proposição de um novo paradigma para a vida humana associada. Esse fato fica evidente na programação do Curso, pois a crítica ao paradigma vigente é apenas uma parcela do Curso, já que a mais significativa trata do novo paradigma e de sua aplicação à realidade. Em vista disso, constituiu também pressuposto do Curso a necessidade de fomentar uma visão crítica de seus integrantes, visando a capacitá-los para desenvolver uma nova forma de pensar e conceber a realidade.

Ainda sobre as mudanças fundamentais que ocorrem em nossa era, cabe enfatizar que o paradigma vigente já não oferece mais sustentação para as novas exigências da vida humana associada. Essas exigências são identificadas pelo clamor das manifestações de rua em prol do bem comum que já ocorriam na década de 1960, fazendo-se presentes até os dias atuais, em diferentes países. Essas manifestações se deram, vale lembrar, a partir da colaboração e cooperação de muitos integrantes da sociedade, em contraposição aos princípios do interesse individual, privado.

Também faz parte dos pressupostos do Curso a necessidade de reordenar a vida humana associada a partir de exigências substantivas que se estendem à participação política, à democracia e ao exercício da cidadania. Essas exigências se fazem presentes em diversos certames, principalmente em manifestações democráticas que se realizam em diferentes países. Elas traduzem demandas por maior participação política, pela eficaz produção do bem público e pela prática da ética nos governos. Portanto, o entendimento que se tem de democracia e da prática da cidadania com base no paradigma vigente também está se esgotando. De fato, o paradigma vigente entende o exercício da democracia como uma delegação que os cidadãos de uma sociedade fazem a seus representantes. Entretanto, esse entendimento de democracia se distanciou da prática de construção da boa sociedade, na medida em que passa a ser sinônimo de luta por vantagens individuais ou de um grupo de interesse. Em outras palavras, a necessidade de superar a unidimensionalização da sociedade e seus efeitos sobre a democracia e a cidadania também se incorporam ao rol dos pressupostos do Curso.

As externalidades surgidas em decorrência da orientação do paradigma de mercado que limitam e colocam em risco a vida humana associada são diversas, podendo alcançar diferentes aspectos da vida humana, da 
sociedade, do mercado e da biosfera. Aqui, a discussão se limita, todavia, ao aspecto político da vida humana e à biosfera, considerada espaço necessário para a sobrevivência dos seres vivos. As sociedades de mercado afastaram as pessoas da esfera pública (ARENDT, 1981; STIVERS, 2010), a ponto de tornarem-se seres isolados. Essa orientação do paradigma de mercado para o privado em detrimento do público agride a integridade do ser humano como animal político a que se referia Aristóteles (BARKER, 1980) e a promessa da política como entendida por Arendt (2008). Tal constatação demonstra como o reducionismo do paradigma de mercado limita o exercício da política, colocando em risco a vida humana associada. Indica, também, que o paradigma de mercado restringe a participação do cidadão na esfera pública.

Também constitui um pressuposto do Curso o entendimento dos limites do ser humano à ação política e às questões que envolvam seu hábitat, a biosfera, que se faz presente desde meados do século passado. $\mathrm{O}$ reducionismo a que levou o paradigma vigente fez com que o cidadão, como ser político, se transformasse em mero detentor de emprego, já não mais capaz de agir, mas apenas de se comportar (ARENDT, 1981). Por seu turno, a biosfera foi sendo apropriada como bem privado, como explica Ardin (1980) na metáfora da tragédia dos comuns. Hoje, a preservação da biosfera se faz mediante a necessidade de cooperação e colaboração entre cidadãos e povos, algo bem distante das premissas do paradigma de mercado. A compreensão desses fatos está na raiz do programa do Curso proposto por Guerreiro Ramos.

As ciências sociais convencionais, por seu turno, não têm um corpo de teoria para explicar as mudanças fundamentais que ocorrem em nossa era, nem oferecem propostas alternativas para superar as externalidades geradas a partir da orientação do paradigma de mercado. Não se pode deixar de reconhecer, no entanto, o esforço da teoria crítica em compor um conjunto de pensamentos que identifiquem os problemas vividos no âmbito das ciências sociais. Entretanto, há necessidade de ir além dessas ideias críticas, explorando o complexo fenômeno das mudanças e as alternativas para superação dos problemas que o paradigma vigente impõe à vida humana associada. Para alcançar esse intento, torna-se necessária a superação dos fundamentos da ciência social vigente, uma vez que, sem um novo olhar, não se pode encontrar o caminho para fazer frente a suas limitações. Torna-se imperativo, portanto, que à teoria crítica levada a efeito por estudioso das ciências sociais se agregue a visão de um novo paradigma que fuja às amarras da sociedade de mercado.

Esse fato constitui um dos mais importantes pressupostos do Curso, haja vista que ele foi concebido a partir da proposta do paradigma paraeconômico formulado por Guerreiro Ramos. As circunstâncias presentes à época em que foi desenvolvido o programa do Curso também indicavam a necessidade de estudar e debater um conjunto de teorias que fossem estruturadas sob um novo paradigma, antagônico ao vigente. A compreensão dessas circunstâncias exigia, portanto, uma reconceitualização semelhante àquela que ocorreu quando se institucionalizou o paradigma de mercado, porém, agora dirigida à reconstrução da vida humana associada, sob a perspectiva da perduração (WHITEHEAD, 2011).

Também constituiu um pressuposto a necessidade de aprender um novo conjunto de conceitos e teorias que fossem aplicados e consentâneos com a transição e as mudanças já visíveis à época em que foi desenvolvido o programa do Curso. Pode-se ir além e afirmar, como o faz o próprio autor na introdução do programa, que esse conjunto de teorias devesse ensejar uma capacidade

[de] articular claramente a natureza dessas mudanças ou encaminhar uma visão compreensiva do emergente "Mundo Novo". [...] É tempo de redescobrir os alicerces sobre os quais o homem será capaz de construir uma vida associada mais rica e harmoniosa do que aquela que as condições da presente época lhe possibilitam. Não é nem mais nem menos do que este o objetivo do presente programa acadêmico e de pesquisa (GUERREIRO RAMOS, 1980, p. 2).

Portanto, identificar e compreender as mudanças no momento em que estão ocorrendo, aprender um conjunto de teorias novas capazes de explicar essas mudanças e compreender o paradigma paraeconômico que traça as linhas gerais de uma nova teoria de alocação de recursos e da vida humana associada constituíam importantes pressupostos do Curso. Entretanto, deve-se acrescentar a esses pressupostos outro, 
não menos importante, que é o imperativo de criar condições de praticabilidade para as propostas formuladas a partir do paradigma paraeconômico.

O conjunto desses pressupostos indica que o Curso foi construído sobre uma visão que associava o profundo conhecimento teórico à necessidade da aplicação desses conhecimentos à realidade prática da vida humana associada. Como afirmava o autor do programa, "é absolutamente necessário que o esforço conceitual de construção teórica [...] revista-se de praticabilidade" (GUERREIRO RAMOS, 1980, p. 9). Deduz-se, por via de consequência, que, entre os pressupostos do Curso estava o de associar à praticabilidade o conhecimento teórico por ele proporcionado. Esse fato evidencia, também, a preocupação de Guerreiro Ramos com a inserção social do Curso.

$\mathrm{Na}$ sequência desses comentários sobre os pressupostos, agora cabe identificar e discutir as teorias que orientaram o Curso. Como descrito na introdução deste artigo, para obter os dados sobre essas teorias, a pesquisa dos documentos se restringiu à contribuição de Guerreiro Ramos, uma vez que se almeja compor um conjunto de conhecimentos como legado que esse intelectual proporcionou à organização e ao desenvolvimento de cursos stricto sensu de pós-graduação em Administração.

\section{Identificação e discussão das teorias que orientaram o Curso}

O resgate que aqui se promove das teorias utilizadas por Guerreiro Ramos para o programa do Curso ocorre a partir do conteúdo da aula inaugural por ele proferida, em maio de 1980, no salão nobre da UFSC; da disciplina básica por ele ministrada, denominada Teoria da Delimitação dos Sistemas Sociais; de outros documentos; além de entrevistas com professores e alunos do Curso.

$\mathrm{Na}$ aula inaugural, Guerreiro Ramos afirmou que o modelo de desenvolvimento preconizado pela Comissão Econômica para a América Latina e o Caribe (Cepal) havia chegado ao final de sua validade histórica. Preconizou a necessidade de uma teoria alocativa de recursos com base na era dos limites, tendo como imperativo que a nova teoria sobre o desenvolvimento fosse formulada a partir dessa base. Esses limites foram associados aos recursos finitos, como o petróleo, e à incapacidade da natureza processar os poluentes gerados pelo processo econômico, fosse pela produção ou pelo consumo. Afirmou Guerreiro Ramos que a consciência desses fatos inspira, também, a delimitação dos sistemas sociais, teoria por ele formulada com o auxílio de pesquisadores de diversos centros de pesquisa. À época, é necessário lembrar, ainda não havia tanta consciência sobre os problemas ecológicos como no presente.

Contudo, é a disciplina denominada Teoria da Delimitação dos Sistemas Sociais, ministrada por Guerreiro Ramos, que contém o principal referencial teórico do Curso, como se depreende da aula inaugural por ele proferida. Como já se relatou no tópico sobre a descrição do Curso, a ementa da disciplina definiu como principal objetivo da disciplina a apresentação e discussão da Teoria da Delimitação dos Sistemas Sociais. Os temas fundamentais da disciplina eram:

- O conceito de racionalidade. Racionalidade instrumental e racionalidade substantiva;

- Ciência social substantiva e ciência social formal;

- A síndrome comportamentalista. Distinção entre comportamento e ação;

- Problemas de formação conceitual. Apropriação incorreta de conceitos;

- Política cognitiva. A psicologia da sociedade de mercado;

- A ciência substantiva das organizações;

- A ciência dos sistemas sociais alternativos;

- A lei da adequação dos requisitos;

- Paraeconomia: modelo multidimensional de alocação de recursos. 
A indicação bibliográfica contida no plano de ensino da disciplina proporcionava aos alunos o referencial básico necessário para o entendimento do conteúdo, como foi possível verificar nas entrevistas com egressos do Curso. É importante lembrar que o livro intitulado A nova ciência das organizações (GUERREIRO RAMOS, 1981) estava no prelo e ainda não havia sido lançado quando do início do Curso. Os alunos receberam uma cópia do material que havia sido enviado para a editora. Com base no conteúdo dessa cópia, agora contido no livro, na bibliografia recomendada para leitura dos alunos e demais fontes de pesquisa já mencionadas, far-se-á uma discussão das teorias contidas em cada um dos temas que orientaram o Curso. Alerta-se, todavia, que essa discussão se restringe a uma breve apreciação, pois do contrário não seria possível esgotar o assunto no espaço deste artigo. Com o propósito de facilitar a leitura deste tópico, o início de cada tema será identificado nos mesmos termos que constam no programa da disciplina.

\section{O conceito de racionalidade. Racionalidade instrumental e racionalidade substantiva}

O conceito de racionalidade é fundamental para o entendimento da Teoria da Delimitação dos Sistemas Sociais, já que Guerreiro Ramos $(1981$, p. 2) a definia "como força ativa na psique humana que habilita o indivíduo a distinguir entre o bem e o mal, entre o conhecimento falso e o verdadeiro e, assim, ordenar sua vida pessoal e social". Percebe-se que o autor confere um sentido ampliado ao termo razão. De um lado, a razão tem um predicado substantivo de distinguir e conhecer, de outro, a capacidade de ordenar e calcular. Esses predicados possibilitam distinguir a racionalidade substantiva da racionalidade instrumental. Embora a razão seja conceituada sob esses dois predicados, não há duas razões, visto que a razão é definida como "uma" força que existe na psique humana, capaz de ordenar a vida. Em outra obra, Guerreiro Ramos (1983) já havia discutido a racionalidade substantiva e a racionalidade instrumental, relacionando-as com a ética, a alienação, a reificação, o poder e a informação.

A discussão da razão leva ao conceito de multidimensionalidade humana, essencial para o entendimento da Teoria da Delimitação dos Sistemas Sociais. A multidimensionalidade nega a ideia reducionista de um ser humano, apenas econômico e social, a ele imputada pelo paradigma vigente. Pelo contrário, o ser humano é um ser político que pertence a uma comunidade de outros seres humanos, mas que também integra a sociedade e a biosfera. Essa concepção do ser humano como um ser político, comunitário, social e integrante da natureza confere uma dimensão maior a ele do que meramente alguém que se comporta como integrante passivo da sociedade, como quer e apregoa o paradigma de mercado. Essa é uma das bases que alicerça a Teoria da Delimitação dos Sistemas Sociais e todo o programa do Curso.

\section{Ciência social substantiva e ciência social formal}

A crítica elaborada por Guerreiro Ramos à ciência social se deve ao modelo de linguagem técnica de que ela faz uso, ao fato de subordinar-se à ciência natural e à visão serialista da existência humana, que reduz o ser humano a mera dimensão social. Essa linguagem perpassa muitas obras das ciências sociais, impregnando, inclusive, a metodologia da pesquisa nessa área. A visão serialista entende a autorrealização humana como um fato histórico, factível de concretizar-se por meio de diversos estágios ao longo do tempo. Essa ideia também se encontra no cerne dos conceitos de desenvolvimento e de modernização que as ciências sociais convencionais apregoaram no passado e, ainda, em muitos casos no presente. Deve-se a essa forma de pensar, promovida pelas ciências sociais convencionais, a dificuldade que alguns povos têm de articular a boa sociedade para seus membros.

A ciência social formal se reveste de alguns aspectos comportamentalistas que limitam ainda mais o seu alcance, principalmente quando utiliza a funcionalização da linguagem e sua orientação centrada em métodos. Nessa condição, a ciência social formal se confunde com uma tecnologia e a sociedade é um mero arranjo social. Aliás, essa é a concepção de sociedade que promove o paradigma de mercado. Como se 
depreende dos documentos do Curso, o entendimento do reducionismo da ciência formal era necessário para que os alunos compreendessem a importância da proposta de uma ciência social substantiva.

A ciência social substantiva, diferentemente da ciência social formal, toma a razão, em seu sentido pleno, como categoria de análise. Os componentes que constituem a ciência social substantiva perduram ao longo dos tempos, não se subordinando ao mero processo de socialização e ao entendimento que separa fatos de valores. Em consonância com essa visão, a Teoria da Delimitação dos Sistemas Sociais inclui em seu arcabouço conceitual a ciência social substantiva, que se ancora na multidimensionalidade humana e nos predicados da razão plena. Sob essa premissa, a ciência social substantiva não separa fatos de valores.

\section{A síndrome comportamentalista. Distinção entre comportamento e ação}

Também compôs a disciplina a discussão em torno da síndrome comportamentalista que, entre outros aspectos, distingue a ação do comportamento. A ação é uma atitude que resulta de escolhas lúcidas, em que o ser humano se empenha, também, em práticas substantivas de vida. A ação está intimamente relacionada com o significado da própria vida. O comportamento, por seu turno, é uma conduta que o ser humano assume a partir de condicionamentos e imperativos externos. Alguns comportamentos compõem os fatos elementares da vida e da sobrevivência, eles se tornam hábitos, outros são frutos da conveniência e da simples adaptação a determinantes sociais. Essas determinantes sociais, usualmente, são reducionistas, pois elas unidimensionalizam o ser humano, tornando-o mero animal social, como os demais que vivem em bando. Nessa condição, fenece a tensão existencial a que se refere Voegelin (1974) e o ser humano perde o significado, o sentido crítico, a capacidade de participação política na comunidade, em suma, ele se reifica e aliena. Ele deixa de ser humano. A síndrome comportamentalista que leva à unidimensionalização promovida pelo paradigma vigente se expressa nessas deformações que acometem o ser humano moderno.

Guerreiro Ramos, na disciplina por ele ministrada no Curso, atribuiu quatro traços à síndrome comportamentalista. A primeira é a fluidez da individualidade, que se sustenta na transitoriedade de valores e na "forma de representação" social que o paradigma vigente legitima a partir de si próprio. Em consulta ao livro que resultou dos documentos distribuídos em aula, constata-se que Guerreiro Ramos (1981, p. 53) entende as diversas formas de representação a partir do pressuposto "de que o universo [...] constitui uma ordem coerente e que a própria comunidade humana é parte dessa ordem". Ele continua afirmando que "A fonte de sua autointerpretação é o paradigma meta-histórico que oferece adequado ponto de referência, como uma estrutura normativa para a conduta humana em geral". A partir dessa estrutura, o ser humano encontra a legitimidade para nortear suas ações e para articular a vida humana associada. A fluidez da individualidade nega esse tipo de legitimidade, ao subordinar a vida do ser humano à transitoriedade dos valores e à forma de representação que se sustenta no processo histórico-social e ao cálculo das conveniências de caráter utilitarista. Como consequência, a fluidez da individualidade contribui e dá espaço para a síndrome comportamentalista.

O perspectivismo é o segundo traço da síndrome comportamentalista. Ele se caracteriza pela conduta humana baseada em conveniências exteriores em que não há espaço para a prática legítima de ações amparadas em um paradigma meta-histórico. O perspectivismo não se estrutura a partir do todo perene, mas sob pontos de vista alheios, em que não há preocupação com a verdade, apenas com as conveniências e interesses exteriores. Nessas condições, fenece a autointerpretação sustentada no paradigma meta-histórico que oferece legitimidade à conduta humana. $\mathrm{O}$ perspectivismo torna legítimo o processo imanente de subordinação completa do ser humano aos ditames sociais. A síndrome comportamentalista prospera nas sociedades em que esse fato passa a integrar a ordem social.

O formalismo é a característica de sociedades em que os padrões éticos substantivos foram substituídos por regras socialmente determinadas que devem ser seguidas pelas pessoas. O formalismo, terceiro traço da síndrome comportamentalista, leva o ser humano à alienação e à reificação, sempre que sua autointerpretação 
não se fizer a partir do paradigma meta-histórico. Da mesma forma, quando os valores da sociedade de mercado regem a vida do ser humano, o formalismo das regras, quase sempre, substitui a orientação ética substantiva. Em outras palavras, o que é formal passa a ser sempre ético, portanto, legítimo como conduta humana. Nesse caso, pode desaparecer a tensão humana que integra permanentemente a vida, bastando ao ser humano comportar-se de acordo com as regras impostas pela sociedade. A síndrome comportamentalista tem no formalismo um de seus mais perversos efeitos sobre a vida humana - ao reduzir o ser humano à dimensão de mero ator social.

Outro traço da síndrome comportamentalista é o operacionalismo. Nele se supõe que toda a realidade social possa ser apreendida por meio de critérios objetivos em que tamanho, forma e extensão podem ser aferidos por meio de mecanismos físicos e matemáticos. O positivismo adotou esse princípio, em que o mundo era constituído como um mecanismo cujo funcionamento poderia ser verificado e avaliado mediante o emprego de meios ao alcance dos sentidos, ou seja, a realidade se resumia ao que os sentidos pudessem identificar. $\mathrm{O}$ comportamento, sob essa condição, podia ser medido e avaliado mediante critérios matemáticos e estatísticos. O operacionalismo, um dos traços da síndrome comportamentalista, também interpreta o ser humano a partir desses mecanismos. Nesse processo, perde-se a compreensão que a ele se atribui quando se discute a forma, a virtude e a beleza como atributos humanos.

\section{Problemas de formação conceitual. Apropriação incorreta de conceitos}

Os problemas de formação conceitual e a apropriação incorreta de conceitos também constituíram formulações teóricas elaboradas por Guerreiro Ramos na disciplina de Teoria da Delimitação dos Sistemas Sociais. Os problemas de formação conceitual e a apropriação incorreta de conceitos ocorrem quando se deslocam teorias, modelos e conceitos para um campo de conhecimento que lhes é estranho, nele não cabem e não lhe dizem respeito. Esse deslocamento pode ser definido como colocação inapropriada de conceitos.

Como exemplo de colocação inapropriada de conceitos, Guerreiro Ramos cita a ilusão da autenticidade corporativa que confunde a organização com o ser humano. Organizações são invenções sociais e, como tais, não carregam o atributo intrínseco de ser ou não autênticas, elas são formais. Outro exemplo citado por Guerreiro Ramos é o da alienação. Quando importada para a teoria organizacional, em especial para a teoria comportamental aplicada às organizações, a alienação passou a ser confundida com um comportamento que pode ser minimizado ou eliminado das organizações formais. A alienação leva o ser humano a perder sua identidade, a se achar um estranho perante si próprio. Portanto, o uso do conceito de alienação é erroneamente apropriado pela teoria comportamental aplicada às organizações.

Outros dois exemplos de colocação inapropriada de conceitos são o de sanidade organizacional e o de pessoas e modelos de sistemas. Deve-se ter em mente que a sanidade é um atributo da natureza do ser humano, não da organização formal. Os teóricos comportamentais que estudam as organizações, ao deslocar o conceito de sanidade das ciências naturais, como atributo do ser humano, para o campo da organização formal, vista como uma invenção social planejada, fizeram uma colocação inapropriada desse conceito. $\mathrm{O}$ mesmo ocorreu quando estudiosos dos modelos de sistemas entenderam que o ser humano poderia ser parte funcional de um sistema. Eles não atentaram para o fato de que o conceito de sistema importado das ciências biológicas não era adequado nem suficiente para explicar o complexo funcionamento da sociedade nem era próprio para lidar com as tensões humanas. O modelo de sistema também não se coaduna completamente com as pessoas. Deve-se ressalvar que alguns modelos de sistemas atuais já apresentam uma arquitetura que leva em consideração as tensões humanas e os limites de interação do ser humano com a organização.

O conhecimento dos problemas de formação conceitual e a apropriação incorreta de conceitos tornam-se relevantes para a Teoria da Delimitação dos Sistemas Sociais, na medida em que ela identifica e faz uma apreciação crítica desses problemas e promove um trabalho restaurativo de cunho científico sobre essa questão, razão pela qual esse conhecimento mostrou-se fundamental para o desenvolvimento do Curso. 
Fica evidente, pois, que a discussão dos problemas de formação conceitual e da apropriação incorreta de conceitos, bem como da política cognitiva e da psicologia da sociedade de mercado, constitui fundamento para a compreensão dos alicerces epistemológicos da nova ciência das organizações e para a organização e desenvolvimento do Curso.

\section{Política cognitiva. A psicologia da sociedade de mercado}

A política cognitiva é o emprego da linguagem para induzir as pessoas ao entendimento da realidade de acordo com os interesses daqueles que praticam esse tipo de política. Ela se mostrou, ao longo da história, uma prática que leva ao desvio da verdade. Os pensadores clássicos gregos já se referem a ela ao criticar o trabalho dos sofistas. De fato, a retórica, como arte da persuasão para distorcer a realidade, foi utilizada pelos sofistas gregos e por suas contrapartes modernas. Para comprovar esses fatos, basta ler os pensadores clássicos gregos, que aos sofistas se referiam com desprezo, ou assistir a programas eleitorais ou comícios dos dias atuais.

A prática da política cognitiva decorre de uma visão simplista do ser humano. Ela parte do pressuposto que ele é um ser puramente social e econômico, que não tem outras motivações senão aquelas inerentes à competição, ao interesse privado e ao cálculo. As teorias que tratam da motivação estão repletas dessa configuração em que o ser humano é um ente que vive o sistema de mercado e seus valores. Também, confiança, autenticidade, autorrealização e pertencimento são termos que se encontram em muitas teorias motivacionais como se fizessem parte, exclusivamente, do espaço organizacional. A linguagem que tenta cingir a vida do ser humano ao espaço organizacional e ao mercado nada mais é do que a prática da política cognitiva voltada à unidimensionalização humana.

A sociedade de mercado é o espaço em que mais prolifera a política cognitiva. Seu emprego está presente em meios de comunicação em geral, quando induzem o consumidor a comprar produtos desnecessários - estes, deixados ao arbítrio do consumidor, provavelmente não seriam adquiridos. Além do emprego pela sociedade de mercado, também nas lides da política se observa largo uso da política cognitiva, em que pese a legislação que impõe limites a essa prática. Na educação formal e nos espaços das organizações formais ela também está presente.

O emprego em que o condicionamento humano é uma constante também se reveste, em muito, da política cognitiva, pois, sem ela, dificilmente o ser humano desempenharia o papel que dele se exige nas organizações formais. O caráter impessoal do desempenho de papel que se exige da pessoa que detém o emprego leva, comumente, à despersonalização e, consequentemente, à alienação. Deve-se ter em mente, todavia, que há uma tensão permanente entre o ser humano e os espaços formais que induzem à unidimensionalização. As diversas fugas, como a busca por grupos informais que as pessoas empreendem nas organizações formais, são uma tentativa de equilíbrio da psique, para superar a impessoalidade do cargo e a alienação.

As técnicas e a linguagem que induzem à reificação que decorre do condicionamento imposto pelo papel do emprego estão eivadas da política cognitiva que, quase sempre, levam a pessoa a entender o espaço organizacional como o espaço da totalidade da vida. Perante esse fato, o que dizer, então, dos cursos de Administração, negócios e, até, de administração pública em que a ciência formal e o conhecimento são o resultado da aplicação dessa política cognitiva? As teorias apresentadas nesses tipos de cursos devem ter resultado de pesquisas ou de sofisticadas formulações científicas. Lamentavelmente, elas não podem ter o nome de teoria, mas de linguagem deturpada para induzir pessoas a acreditar em uma distorcida realidade.

A sociedade de mercado alimenta sua perpetuação por meio da linguagem instrumental em que se reforça a prática da política cognitiva. Os meios de comunicação de massa são portadores de mensagens que reforçam a ideia de que o mercado e seus aparatos são sinônimos da existência humana. Nesses casos, o significado, 
essencial para a vida humana, se restringe, em sua quase totalidade, ao emprego e ao consumo de bens que estão além das necessidades básicas. Nesse tipo de sociedade, em que a comunicação de massa viceja, é quase impossível ao ser humano fugir dessas condicionantes impregnadas da política cognitiva. A teorização da Administração convencional, seja ela direcionada à administração de empresas ou à administração pública, quando almeja tornar-se verdadeiramente científica, precisa reconhecer as distorções que lhe são inerentes, fruto da prática da política cognitiva. Os pesquisadores da teoria crítica têm nesse campo um manancial nada desprezível para seu trabalho.

\section{A ciência substantiva das organizações}

A ciência substantiva das organizações estrutura-se a partir de uma base epistemológica que segue os primados da racionalidade substantiva. Aliás, todas as organizações são, também, sistemas epistemológicos, ou seja, elas são interpretadas a partir de categorias preestabelecidas. Assim, as organizações formais levam seus membros a interpretá-las segundo categorias que elas entendem estrategicamente necessárias aos seus interesses. Esse fato dá a dimensão da influência que podem exercer sobre as pessoas a partir das categorias que elas entendem como necessárias para que sejam interpretadas de acordo com os propósitos que a elas servem. Usualmente, o sistema epistemológico das organizações está oculto, portanto, pouco ou nada elaborado por seus membros. Ele se traduz por um conjunto de regras, mediante as quais a realidade da organização, tanto interna quanto externa, é vivenciada em termos práticos. Ao alterar o sistema epistemológico de uma organização, pode-se levar a perda da estabilidade interna, queda e mesmo fracasso na produtividade e confusão na interpretação do ambiente exterior à organização.

No âmbito das organizações, além do sistema epistemológico que lhe proporciona identidade, também há interação simbólica entre seus membros. A ação calculista que ocorre na organização formal é classificada como interação simbólica primária, uma vez que as finalidades da vida são diversas e poucas delas cabem nesse tipo de organização. A interação simbólica não é apenas um meio ou instrumento para o alcance de objetivos formalmente definidos, ela é um fim em si próprio, porque integra o âmago do ser humano e permite aos membros de uma sociedade a experiência de sua essência.

As teorias de interação simbólica, entre as quais não se encontra a teoria organizacional, partem do princípio de que o conhecimento pode ser obtido de inúmeras maneiras, sendo a ciência, como a concebemos hoje, apenas uma delas. Por seu turno, a teoria organizacional pressupõe que a sociedade é a existência social, não levando em conta a permanente tensão entre a singularidade do ser humano e ela própria. A interação simbólica se faz de pessoa a pessoa, mediante a experiência direta da realidade, quase sempre por meio da comunicação não formal.

As organizações formais, em que impera o emprego que se caracteriza como trabalho, não são ambientes adequados para a interação simbólica. Há, todavia, outros tantos espaços sociais em que as pessoas podem se ocupar com atividades as mais diversas, em que a interação simbólica constitui fator primordial para o exercício da vida humana.

\section{A ciência dos sistemas sociais alternativos}

A delimitação dos sistemas sociais entende que o ser humano, para a plena realização de sua existência, requer múltiplos espaços de vida em que ele realiza a interação simbólica. É necessário alertar que um desses espaços é a organização formal e outro é o mercado, quando necessariamente delimitados e restritos aos objetivos de produção. Da mesma forma, o condicionamento que se exige do ser humano no espaço organizacional não é aceitável como um imperativo para toda a vida. A teoria substantiva da organização tem, entre seus propósitos, minimizar as imposições e os desvios que esse condicionamento impõe à 
existência humana. Tem, ainda, o objetivo de definir como necessária à autorrealização humana, a existência de múltiplos espaços para que a vida possa se dar em sua plenitude. As organizações substantivas são um desses espaços onde é possível a autorrealização humana por meio do exercício pleno da vida. Em muitos sistemas sociais alternativos, essas organizações florescem, não por negar a realidade, mas por se constituírem a partir de sistemas epistemológicos, baseados no exercício pleno da razão, em que a interação simbólica é possível.

A teoria da delimitação dos sistemas sociais tem distintas formas de orientação e de categorias que se fazem presentes na sociedade. Essas formas e categorias se apresentam nas seguintes modalidades:

- orientação comunitária: a economia, a horda e a isonomia;

- orientação individual: o isolado, anomia e a fenonomia;

- prescrição: a economia e o isolado;

- ausência de normas: a horda e a anomia.

Essas modalidades são autoexplicativas, no entanto, cabe um pequeno comentário sobre cada uma dessas categorias. A economia é um ambiente formal. A horda é uma coletividade sem senso de ordem. A isonomia é um contexto que se orienta pela igualdade e pode ser caracterizado como um espaço em que a tomada de decisões é compartilhada por todos os seus membros, as relações entre os seus componentes são primárias, a liderança interna resulta da escolha de todos e as pessoas nela se ocupam em atividades que possibilitam a autorrealização. O isolado é um indivíduo que não vê a possibilidade objetiva de agir no mundo, pelo contrário, ele aceita as circunstâncias como modeladoras de sua vida pessoal. A fenonomia é um espaço constituído por um ou poucos indivíduos; nele há automotivação para a criatividade, o resultado econômico das atividades é incidental, quase nulo, e a ocupação traduz uma vocação. A anomia é um caso de orientação individual, mas sem o arcabouço de normas sociais; ela é constituída por pessoas marginais à sociedade.

\section{A lei da adequação dos requisitos}

A lei da adequação dos requisitos, outra teoria abordada por Guerreiro Ramos, determina que haja múltiplos sistemas sociais em uma sociedade para que ela possa oferecer as condições necessárias para a autorrealização de seus membros. Estabelece, ainda, que cada um desses sistemas tenha requisitos próprios de planejamento. Para a consecução dessa atividade, que requer interação entre o planejador e a comunidade, há necessidade de levar em conta algumas dimensões básicas de qualquer sistema social. São elas:

- Tecnologia;

- Tamanho;

- Cognição;

- Espaço;

- Tempo.

A tecnologia se constitui de normas, comportamentos e instrumentos por meio dos quais os resultados são produzidos. O tamanho dos sistemas sociais é uma condição essencial para que as relações e a interação simbólica entre os membros de um sistema social sejam possíveis. A cognição trata das formas de conhecimento em uso em cada sistema social. O sistema cognitivo pode ser funcional, político, personalístico e deformado. O espaço constitui condição necessária e básica de cada sistema social. Perante a lei da adequação dos requisitos, cada sistema social deve ter o espaço necessário para realização de seus propósitos. Embora isso compreenda a lógica mais elementar, a realidade demonstra que o sistema de 
mercado abrange quase todo o espaço para a existência humana. O desenho do espaço em diferentes sistemas sociais também deve levar em conta que podem ser criados sistemas sociais socioafastadores e outros que são socioaproximadores.

O tempo é outra dimensão dos sistemas sociais. Ele tem uma relação muito íntima com o espaço e a cognição e com as categorias que integram os sistemas sociais. $\mathrm{O}$ tempo pode ser entendido, de acordo com o uso que dele se faz, como: tempo serial ou linear, convivial, de salto e errante. O tempo linear diz respeito aos sistemas formais, associando-se à ideia de duração da vida. $\mathrm{O}$ tempo convivial se refere à sociabilidade do ser humano. Ele é próprio de espaços isonômicos. O tempo de salto é pessoal e ocorre quando o ser humano se abstrai, medita ou exercita o pensamento, entendido como uma conversa consigo próprio. Essa modalidade de tempo também é conhecida como tempo eterno. O tempo errante pode ser associado à anomia e às hordas. Como se observa, as categorias que compõem os sistemas sociais, no entendimento da teoria da delimitação dos sistemas sociais, apontam distintas e diferentes formas de orientação quanto à tecnologia, tamanho, cognição, espaço e tempo. Essa premissa é corroborada pela lei da adequação dos requisitos, um dos fundamentos da teoria da delimitação dos sistemas sociais.

\section{Paraeconomia: modelo multidimensional de alocação de recursos}

A paraeconomia, como um modelo multidimensional para a alocação ótima de recursos, pode ser entendida como uma teoria política substantiva de relacionamento entre enclaves, com o propósito de criar e oferecer os meios necessários ao desenvolvimento de condições substantivas de vida. O paradigma paraeconômico, em sua essência, define uma nova visão de sociedade constituída por diferentes sistemas em que o ser humano pode buscar objetivos distintos que ensejam a autorrealização. Ele define, também, que a economia não deve ser um sistema livre de qualquer controle, mas regulada por meio da ação política, o que não quer dizer pela burocracia do estado. Ainda consta da orientação do paradigma o entendimento de que tanto o mercado como outros sistemas sociais são responsáveis pela produção. Por via de consequência, os critérios que orientam a produção não podem ser definidos apenas com base economicista. Também define que tanto a economia de troca - as transferências bidirecionais - como a economia comunitária - transferências unidirecionais - são necessárias para implementar decisões e políticas sociais alocativas. Portanto, a análise convencional de custo-benefício não é suficiente para avaliar as contribuições dos fatores de produção para a viabilidade do todo social. Deduz-se que o paradigma paraeconômico incorpora os conceitos de multidimensionalidade humana e de sociedade multicêntrica como estratégias para a alocação dos recursos.

Feitas essas breves apreciações sobre os pressupostos e os fundamentos teóricos que orientaram o Curso, parte-se agora para o tópico seguinte que contém uma síntese do legado que Guerreiro Ramos proporcionou à organização e ao desenvolvimento de cursos stricto sensu de pós-graduação em Administração.

\section{Considerações finais sobre o legado do Curso}

Este estudo teve por objetivo identificar e discutir os pressupostos e os fundamentos teóricos que orientaram o Curso de Mestrado em Planejamento Governamental, desenvolvido por Alberto Guerreiro Ramos na UFSC em 1980 e 1981. Alcançado esse objetivo, cabe agora extrair desses pressupostos e teorias, analisados como um conjunto de conhecimentos, o legado que esse intelectual proporcionou à organização e ao desenvolvimento de cursos stricto sensu de pós-graduação em Administração. Essa tarefa, contudo, mostrase no campo do impossível diante da amplitude do conjunto desses conhecimentos, razão pela qual o legado que se apresenta nestas considerações finais se restringe a alguns excertos que se espera representem uma amostra desse legado.

Feitas essas importantes considerações preliminares, apresenta-se na sequência um rol de enunciados e proposições que constituem o excerto do legado de Guerreiro Ramos para a organização e o desenvolvimento de cursos stricto sensu de pós-graduação em Administração. 
- A elaboração da teoria da delimitação dos sistemas sociais e o paradigma paraeconômico como norteadores da vida humana individual e associada.

- A compreensão de que o curso stricto sensu de pós-graduação em Administração é um empreendimento científico que se constitui e se desenvolve a partir de uma base ontológica, um sistema epistemológico e um corpo de teorias, métodos e técnicas que, em seu conjunto, são essenciais para a autointerpretação de seus membros.

- O Curso de Planejamento Governamental, por seu conteúdo singular, como empreendimento científico, por si só é um legado.

- A compreensão do paradigma de mercado e de suas origens, bem como a base ontológica e epistemológica que sustenta o entendimento sobre a multidimensionalidade humana, a racionalidade substantiva e instrumental e a sociedade multicêntrica são condições necessárias para a organização e o desenvolvimento de cursos de pós-graduação stricto sensu em Administração.

- O potencial intrínseco que têm os cursos de pós-graduação stricto sensu em Administração para auxiliar as comunidades que se articulam em busca da autossustentabilidade, quando organizados e desenvolvidos a partir das premissas expostas por Guerreiro Ramos.

- A constatação de que os estudos avançados em Administração se sustentam a partir de sua profundidade teórica e entendimento da realidade complexa, que inclui tanto os aspectos instrumentais quanto os substantivos da vida humana associada.

- O entendimento de que a multidisciplinaridade, nos moldes convencionais, utilizada em cursos que adotam como orientação o paradigma vigente, não é suficiente para fazer frente às mudanças que ocorrem em nossa era.

- A necessidade de se aprender um novo conjunto de conceitos e teorias que sejam consentâneos com a transição e as mudanças que já eram visíveis à época em que foi desenvolvido o programa do Curso organizado e desenvolvido por Guerreiro Ramos.

- O estímulo à criação de centros de estudos que sejam ordenados e estruturados sob um novo paradigma capaz de interpretar e compreender as mudanças no momento em que elas ocorrem.

- A necessidade premente dos cursos se estruturarem a partir de bases epistemológicas que superem o paradigma vigente e de organizar e desenvolver suas disciplinas calcadas nos primados de uma visão alternativa de sociedade.

- O imperativo de que os cursos de pós-graduação, tanto em sua organização como em seu desenvolvimento, tenham presente o declínio da sociedade de mercado e do paradigma que a sustenta, assim também, o caráter delimitativo já evidente em muitas formas de ordenamento do ser humano, da comunidade e de proteção da biosfera.

- A constatação dos limites e mesmo a incapacidade das ciências sociais para explicar o complexo fenômeno das mudanças que a sociedade vivencia.

- A necessidade de fomentar junto aos integrantes desses cursos uma visão crítica para capacitá-los a desenvolver uma nova forma de pensar e de conceber a realidade.

- O reconhecimento e as decorrências do fato de que os participantes desses cursos são seres humanos que têm o privilégio da participação política e do exercício da cidadania, que, em seu conjunto, integram as relações de interação simbólica que ocorrem entre eles.

- As considerações sobre a multidimensionalidade humana das quais se deduz que cada participante do curso é um centro de aprendizagem e, como tal, uma fonte de criatividade e de saber.

- O entendimento, necessariamente presente em todo o curso, da teoria dos limites que acometem, nos dias atuais, a comunidade, o ser humano e seu hábitat, que é a biosfera. 
- A necessidade de que a teoria crítica desenvolvida em cursos de pós-graduação stricto sensu em Administração se faça acompanhar de propostas estruturadas em um paradigma antagônico ao vigente.

- Atenção para o reducionismo da ciência social formal que, ao contrário da ciência social substantiva, não separa fatos de valores.

- A distinção entre ação e comportamento e sua relação com a ética, a reificação e a alienação e a fluidez da individualidade, nos termos que são conceituados pelo novo paradigma.

- A constatação de que a colocação inapropriada dos conceitos nas ciências sociais leva à consequente necessidade de um trabalho restaurativo de reconceitualizar muitos de seus termos.

- Atenção para a prática da política cognitiva que distorce a realidade e induz a pesquisa a erro, fato presente no conteúdo de muitas teorias que se ensinam, conscientemente ou não, nos cursos de pósgraduação stricto sensu em Administração.

- A constatação de que as organizações não são sistemas destituídos de valores, pelo contrário, elas são sistemas epistemológicos que induzem as pessoas a interpretar a realidade a partir dos propósitos aos quais elas servem, premissa que é basilar na organização e desenvolvimento de cursos de pósgraduação stricto sensu em Administração.

- O resgate e a discussão das interações simbólicas como fato essencial na vida dos seres humanos que transcende o espaço da organização formal. Nos cursos de pós-graduação, as interações simbólicas também se realizam, inclusive na relação entre professores e alunos.

- Atenção para o fato de que os cursos de pós-graduação stricto senso em Administração também devem estar a serviço da pesquisa de outras categorias, além da economia e do mercado, devendo alcançar a isonomia, a fenonomia, a anomia, o isolado e a horda.

- O desenvolvimento da lei da adequação dos requisitos que estatui a sociedade como um conjunto de múltiplos sistemas sociais. A partir dessa lei, a organização e o desenvolvimento de cursos de pósgraduação devem levar em conta as dimensões básicas desses sistemas, entre as quais estão: tecnologia, tamanho, cognição, espaço e tempo. A compreensão dessas categorias pode ensejar outras possibilidades que os cursos convencionais não propiciam.

- A constatação de que a preservação da biosfera leva à necessidade de cooperação e colaboração entre cidadãos e povos, algo bem distante das premissas do paradigma de mercado. A compreensão desses fatos, em que prevalece a multidimensionalidade humana, deve integrar a organização e o desenvolvimento desses cursos, como o foi no Curso de Planejamento Governamental, proposto por Guerreiro Ramos.

Essas proposições e enunciados foram extraídos do conjunto de conhecimentos elaborado a partir dos pressupostos e fundamentos teóricos que orientaram o Curso de Mestrado em Planejamento Governamental desenvolvido por Alberto Guerreiro Ramos. Diante da amplitude do conjunto desses conhecimentos, eles compõem, tão somente, uma parcela do legado que esse intelectual propiciou à academia, em especial, à organização e ao desenvolvimento de cursos stricto sensu de pós-graduação em Administração.

A adoção desse legado depende, antes de tudo, da consciência e do conhecimento que se tem de seus termos, da compreensão das grandes mudanças de nossa era e do comprometimento com a prática de uma ciência social substantiva. Entretanto, esses são desafios em nada impossíveis de superar por parte daqueles que se dedicam às lides do ensino e da pesquisa como uma opção substantiva de vida. 


\section{Referências}

APPLEBY, J. O. Economic thought and ideology in seventeenth-century England. Princeton: Princeton University Press, 1978.

ARDIN, G. The tragedy of the commons. In: DALE, H. (Ed.). Economics, ecology and ethics. San Francisco: W. H. Freeman, 1980 .

ARENDT, H. A condição humana. Rio de Janeiro/São Paulo: Forense Universitária/Edusp, 1981.

ARENDT, H. A promessa da política. Rio de Janeiro: Bertrand Brasil, 2008.

BARKER, E. The politics of Aristotle. New York: Oxford University Press, 1980.

GUERREIRO RAMOS, A. Programa acadêmico e de pesquisa em planejamento governamental. In: GUERREIRO RAMOS, A. Cadernos do curso de Pós-Graduação em Administração. Florianópolis: UFSC, 1980.

GUERREIRO RAMOS, A. A nova ciência das organizações: uma reconceitualização da riqueza das nações. Rio de Janeiro: Ed. FGV, 1981.

GUERREIRO RAMOS, A. Administração e contexto brasileiro: esboço de uma teoria geral da administração. Rio de Janeiro: FGV, 1983.

GUERREIRO RAMOS, A. A redução sociológica. 3. ed. Rio de Janeiro: Ed. UFRJ, 1996.

HIRSCHMAN, A. As paixões e os interesses: argumentos políticos para o capitalismo antes de seu triunfo. 2. ed. São Paulo: Paz e Terra, 2002.

JAGER, W. Paidéia, a formação do homem grego. São Paulo: Martins Fontes, 1995.

MARCUSE, H. A ideologia da sociedade industrial. Rio de Janeiro: Zahar, 1979.

MEAD, G. H. Mind, self, and society: From the standpoint of a social behaviorist. v. 1. Chicago: University of Chicago Press, 2009.

POLANYI, K. A grande transformação: as origens da nossa época. Rio de Janeiro: Campus, 1980.

VOEGELIN, E. Reason: the classic experience. Baton Rouge, LA: Louisiana State University Press, 1974.

VOEGELIN, E. From Enlightment to Revolution. Durham: Duke University Press, 1975.

VOEGELIN, E. Anamnesis. South Bend, IN: University of Notre Dame, 1978.

VOEGELIN, E. A nova ciência da política. Brasília: UnB, 1979.

WHITEHEAD, A. N. Science and the modern world. Cambridge: Cambridge University Press, 2011. 